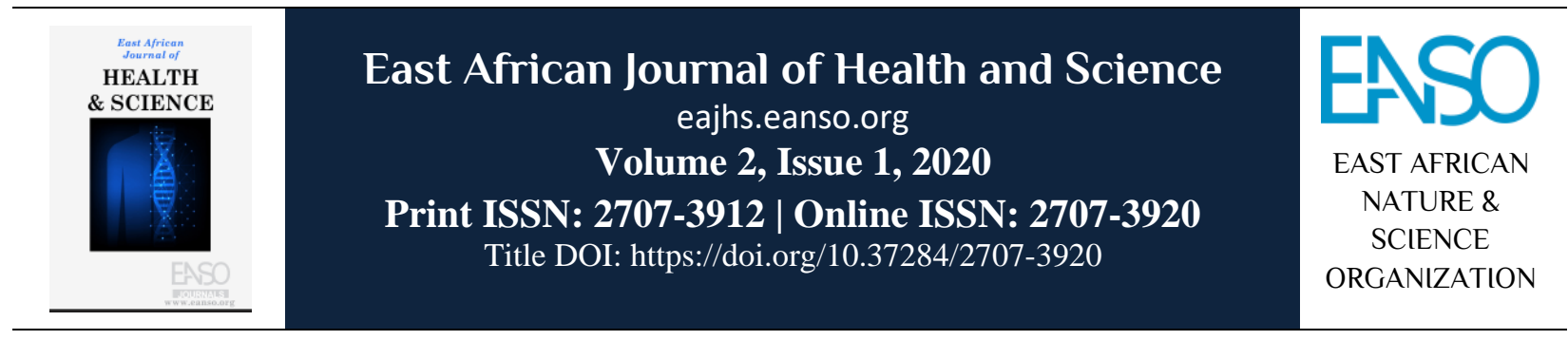

Original Article

\title{
Characteristics and Prevalence of Depression Symptoms in Caregivers of Patients Undergoing Palliative Care
}

\author{
Elizabeth A. Adol, Prof. Ann Obondo* \& Dr. Pius Kigamwa \\ Department of Psychiatry, University of Nairobi, P. O. Box 30197 - 00100 (GPO), Nairobi, Kenya. \\ *Author for correspondence email: obondo@uonbi.ac.ke.
}

Article DOI: https://doi.org/10.37284/eajhs.2.1.120

\author{
Article history: \\ Received: 19 Feb 2020 \\ Accepted: 26 Feb 2020 \\ Published: 2 Mar 2020 \\ Keywords: \\ Depression, \\ Depression Symptoms, \\ Palliative Care, \\ Caregivers, \\ Prevalence of \\ Depression
}

\begin{abstract}
Family role in taking care of patients undergoing palliative care leads to complex, multidimensional responsibility which may have consequences to the mental health of primary caregivers. Studies have shown that 40 to 70 per cent of caregivers experience symptoms of depression. The general objective of this study was to determine the characteristics and prevalence of depressive symptoms among caregivers of patients in palliative care. The population comprised of caregivers of patients undergoing palliative care at the Kenyatta National Hospital. A cross-sectional study was used where questionnaires were administered using Beck's Depression Inventory and a researcher designed socio-demographic characteristics questionnaire for the caregivers. The results showed that $62.7 \%$ of the caregivers presented with symptoms of depression. This is four times higher as compared to the general population. The severity of the depressive symptoms ranged from mild to severe with the majority experiencing symptoms of severe depression. Spousal caregivers had the highest prevalence of depressive symptoms followed by those who were taking care of their children. The recommendations include having healthcare providers do routine screening for depression in family caregivers and not just on patients alone.
\end{abstract}

\section{APA CITATION}

Adol, E., Obondo, A., \& Kigamwa, P. (2020). Characteristics and Prevalence of Depression Symptoms in Caregivers of Patients Undergoing Palliative Care. East African Journal of Health and Science, 2(1), 1-8. https://doi.org/10.37284/eajhs.2.1.120

\section{CHICAGO CITATION}

Adol, Elizabeth, Ann Obondo, and Pius Kigamwa. 2020. "Characteristics and Prevalence of Depression Symptoms in Caregivers of Patients Undergoing Palliative Care". East African Journal of Health and Science 2 (1), 1-8. https://doi.org/10.37284/eajhs.2.1.120. 


\section{HARVARD CITATION}

Adol, E., Obondo, A. and Kigamwa, P. 2020. "Characteristics and Prevalence of Depression Symptoms in Caregivers of Patients Undergoing Palliative Care", East African Journal of Health and Science, 2(1), pp. 1-8. doi: 10.37284/eajhs.2.1.120.

\section{IEEE CITATION}

E. Adol, A. Obondo, and P. Kigamwa, "Characteristics and Prevalence of Depression Symptoms in Caregivers of Patients Undergoing Palliative Care", EAJHS, vol. 2, no. 1, pp. 1-8, Mar. 2020.

\section{MLA CITATION}

Adol, Elizabeth A., Ann Obondo, and Pius Kigamwa. "Characteristics and Prevalence of Depression Symptoms in Caregivers of Patients Undergoing Palliative Care". East African Journal of Health and Science, Vol. 2, no. 1, Mar. 2020, pp. 1-8, doi:10.37284/eajhs.2.1.120.

\section{INTRODUCTION}

Depression is commonly linked with stress, anxiety and in the ability of an individual to change the situation at hand. Caregiving might not cause depression, but the caregiver can undergo anxiety, emotional and physical strain experience when taking care of the patient especially a family member. The negative feeling often drains the caregiver's strength and frequency leading to anger, crying and anxiety which are symptoms of depression (Rivera, 2009). Studies show that 40 to 70 per cent of caregivers' experience symptoms of depression (Aoun, Kristjanson, Currow, \& Hudson, 2005). Many caregivers do not take time to eat well, exercise or see their own doctor. Some studies show that caregivers have a higher rate of high blood pressure and heart disease as opposed to noncaregivers of the same age (Chen \& Hu, 2002).

Identifying caregivers with depression is, therefore, necessary not only for the physical and emotional health of the caregiver but also for the sake of the quality of care of the patient. When the caregiver is unwell, the quality of care will be ultimately compromised. Many chronically ill patients are now commonly managed at home and home-based care is recommended due to a friendly environment as well as cost reduction measure in healthcare. This study attempted to fill the existing gap in the literature on the involvements of primary caregivers by highlighting the experiences and challenges leading to depression faced by these family caregivers to patients with a terminal illness. It provides more knowledge on the impact of the caregiving role and explores caregiver characteristics associated with caregiver depressive symptoms in the palliative care unit at the Kenyatta National Hospital.

\section{LITERATURE REVIEW}

Most of the literature associated with caregivers is rooted in the model of McMillan's modified Emanuel and Emanuel Model of a Peaceful Death to predict hospice cancer caregivers' depressive symptoms (Bemporad, 1988). The model indicates that both caregiver and patient fixed as well as modified physical and psychosocial factors contribute to caregiver depressive symptoms. Caregiver's age, ethnicity, gender, health status, depression history, and relationship to the patient are linked to caregiver depression. Some the modifiable factors which vary with caregivers depressive symptoms either positively or negatively are coping skills, burden, mastery of patient care, attitude, quality of life and the caregivers' perception of social support, depressive symptoms, functional status, patients' symptom distress, and sense of coherence (Bemporad, 1988).

\section{Palliative Care Concept}

Palliative care refers to specialized medical care for people with serious illnesses. The care is crucial and different from the normal care since it provides patient with extra care which assists in relieving pain, stress, adverse reactions, symptoms and emergencies that might arise when prognosis changes in physical health. The care assists the patient and family in improving the quality of life. Palliative care is engaging other special teams like nurses, doctors and specialist to provide extra support to the patients for quick recover. It is appropriate at any age and at any stage of a serious illness and can be provided along with curative treatment (Seymour, Clark, \& Winslow, 2004). 


\section{Prevalence of Depression Symptoms in Caregivers}

Life-threatening illnesses like cancer affect the entire family because it impacts the financial, social and physical wellbeing of their family member. Family member forms the closest bound between the patient and close family making it a primary responsibility and care for support socially, economically and health-wise (Baider, Kaufman, Manor, Ever-Hadani, \& Kaplan, 1996). The current trend in hospitals involves increased outpatient care aimed at reducing hospital stay period due to limited beds to handle palliative care patient and accompanied high financial implication of hospital stay. This incentivizes the transfer of caregiving to homecare where the patient is taken care of from their home setting. Therefore, family members become the primary care provider since they are immediate support to the patient (Cameron, Shin, Williams, \& Stewart, 2004).

The role of family caregivers has shifted from one of custodial care to a complex, multifaceted role that included symptom management, monitoring for changes in hallmark symptoms, equipment care, patient transport and advocacy, and management of activities/responsibilities the patient has foregone because of illness (Cameron, Shin, Williams, \& Stewart, 2004; Given, Given, \& Kozachik, 2001). Due to advances in treatment, the cancer care trajectory has increased from days and weeks to months and years meaning the period of survival is longer (Given, Given, \& Kozachik, 2001). Emotional, financial and physical distress is the major challenge and cause of depression to caregivers in home-based setup primary healthcare (Ferrario, Cardillo, Vicario, Balzarini, \& Zotti, 2004). In another longitudinal study, the results revealed that caregivers experienced substantial psychological morbidity (anxiety and depression) at the beginning of the patient's palliative illness (Grunfeld, et al., 2004). The anxiety and depression were as results of a considerable increase in caregiver depression and burden when a patient reaches the final stages of the illness (Grunfeld, et al., 2004). Similarly, psychological morbidity (anxiety and depression) was found to have an equal or greater impact on the caregiver than the patient (Weitzner, McMillan, \& Jacobsen, 1999). Patient's physical and emotional factors were found to forecast caregiver's suffering as well as a burden which was strong predictors of anxiety and depression. This results from the family caregivers not able to understand why the illness, inability to give care, controls the patient's symptoms inducing anxiety and depression (Hinds, 1985).

\section{Characteristics for Depression Symptomatology in Care Giver}

There are gender differences in depression symptoms among female caregivers; they mainly entail a high level of anxiety and depression symptoms as compared to the male counterpart caregiver (Beeson, 2003). Women have emotional feelings that are attached to the patient than male hence higher rates of depressive symptoms. They are most likely to be socially isolated and have almost twice the rate of probable major depression than men (Gallicchio, Siddiqi, Langenberg, \& Baumgarten, 2002). Other studies have also argued that male caregivers might also have higher rates of depressive symptoms since the male gender hide their depression and anxiety symptoms (Siegel, Karus, Raveis, Christ, \& Mesagno, 1996). Male spousal caregivers of patients have had depressive symptoms scores significant for a diagnosis of depression (Shanks-McElroy \& Strobino, 2001).

Age characteristic is also another concept that affects depression symptoms. Younger caregivers are associated with higher depression symptoms than the older gender (Butler, Turner, Kaye, Ruffin, \& Downey, 2005). Middle-aged caregivers may be caring for a parent while raising their own children with additional family and employment responsibilities. Dementia caregivers older than 65 years have also been found to have depressive symptom levels high enough to be classified as clinically depressed (Covinsky, et al., 2003). However, caregiver age has not been found predictive of caregiver depressive symptoms (Butler, Turner, Kaye, Ruffin, \& Downey, 2005).

\section{RESEARCH METHODOLOGY}

This was a cross-sectional study; the method was better suited to examine the experiences of caregivers of patients receiving palliative care at the Palliative Care Unit at KNH. The study was carried out in Kenyatta National Hospital (KNH), Nairobi 
County, Kenya. The study targeted 160 caregivers where a sample of 114 caregivers was selected. Both Becks Depression Inventory (BDI) and sociodemographic survey tools were used. Descriptive statistics were used to analyze the data.

\section{RESULTS AND DISCUSSION}

The findings of the study elucidated that most caregivers were family members. They constitute spouses (43.6\%) and parents (41.8\%); others $(12.7 \%)$ were still part of a family other than spouse and parent who included children or siblings to the patients. There was a very significant relationship (statistically) between the relationship with the patient and depression $(\mathrm{p}=0.000)$.

Table 1: Age and Depression BDI Score

\begin{tabular}{lllllll}
\hline Age & & $\begin{array}{l}\text { BDI Score } \\
\mathbf{0 - 9}\end{array}$ & $\begin{array}{l}\mathbf{1 0 - 1 8} \\
\text { (Minimal) }\end{array}$ & $\begin{array}{l}\mathbf{1 9 - 2 9} \\
\text { (Mild) }\end{array}$ & $\begin{array}{l}\mathbf{3 0 - 6 3} \\
\text { (Moderate) }\end{array}$ & Total \\
& & 3 & 0 & 9 & 0 & 12 \\
\hline $18-28$ & Count & 15.8 & .0 & 19.6 & .0 & 10.9 \\
& \% within BDI Score & 0 & 4 & 11 & 6 & 21 \\
$29-39$ & Count & .0 & 18.2 & 23.9 & 26.1 & 19.1 \\
& \% within BDI Score & 11 & 15 & 12 & 10 & 48 \\
$40-50$ & Count & 57.9 & 68.2 & 26.1 & 43.5 & 43.6 \\
& \% within BDI Score & 5 & 3 & 12 & 7 & 27 \\
$51-60$ & Count & 26.3 & 13.6 & 26.1 & 30.4 & 24.5 \\
& \% within BDI Score & 0 & 0 & 2 & 0 & 2 \\
& Count & .0 & .0 & 4.3 & .0 & 1.8 \\
& \% within BDI Score & 19 & 22 & 46 & 23 & 110 \\
& Count & 100.0 & 100.0 & 100.0 & 100.0 & 100.0 \\
\hline
\end{tabular}

Table 1 revealed that the relationship between age and depression of caregiver. The respondents between the age of 40-50 years are more likely to experience higher levels of depression as compared to other age groups i.e. the age group between the age of 40-50 years $10(43.5 \%)$ had severe depression as compared to 51-60 years at $7(30.4 \%)$ and 29-39 years at $6(26.1 \%)$. Thus there is a statistically significant association between the age group and level of depression $\left(\chi^{2}(12)=24.683, p \geq\right.$ 0.016). 
Figure 1: Caregiver Duration of Care and Depression

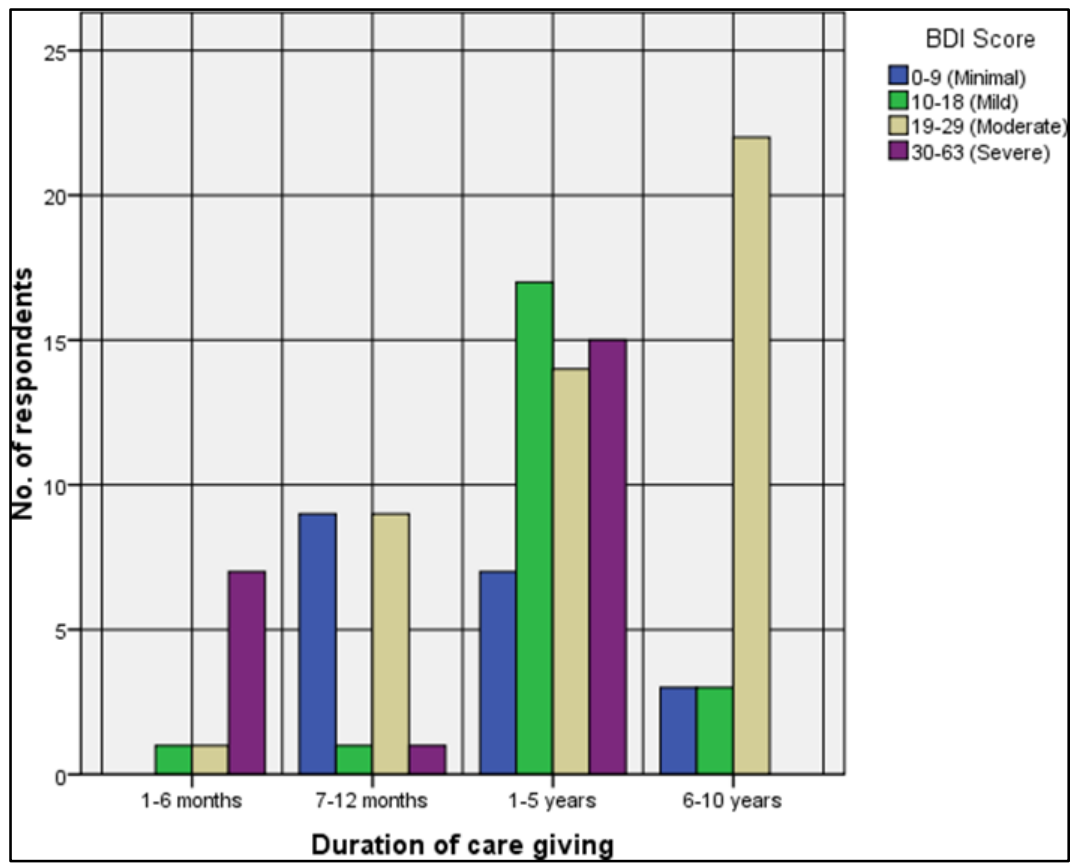

Figure 1 revealed that respondent with 6-10 years duration of care was more likely to suffer from a moderate level of depression $22(47.8 \%)$ while those with a duration of care between 1-5 years were more likely to have a severe level of depression at $15(65.2 \%)$. For the duration of care variable, the chi-square obtained is 57.05 with 9 degrees of freedom and a significance level of .000, which falls well below the .05 alpha levels, the difference between the observed and expected values is significant. Thus, there is a statistically significant association between duration of care level of depression recorded $\left(\chi^{2}(9)=57.048, p \geq\right.$ $0.000)$.

Figure 2: Caregiver Relationship with the Patient and Depression

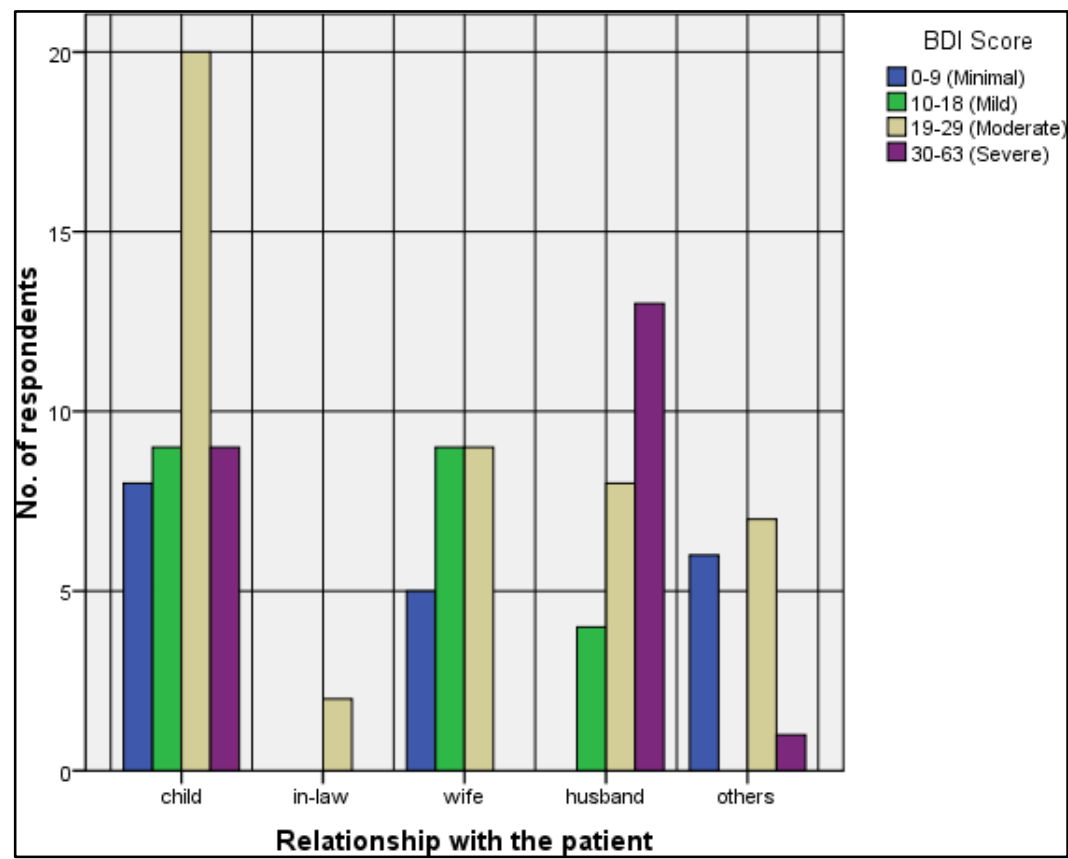


Figure 2 showed that wives were more likely to suffer from severe depression while their husbands were sick i.e. severe depression levels at $13(56.5 \%)$ as compared to those who were taking care of their children who had a moderate depression level of 20 (43.5\%) and husbands with mild depression levels at $9(40.9 \%)$. Hence, for the care giver's relationship with patient variable the chi-square obtained is 38.431 with 12 degrees of freedom and a significance level of .000 , which falls well below the .05 alpha level, the difference between the observed and expected values is significant. Thus, there is a statistically significant association between caregiver relationship and level of depression recorded $\{\chi 2(12)=38.431, p \geq 0.000\}$.

In this study, the adult child may have been captured in the others further showing an association between the relationship and depression. A study found that the family was a major factor in the individual's health process and played a prime role in the course and management of illness (Wright \& Leahey, 2005; Weihs, Fisher, $\&$ Baird, 2002). Patients and their caregivers are now commonly based in their homes with complicated medical therapies to be administered. These changes placed greater demands for caregivers and 'informal' support structure for patients. The caregiver role could dramatically impact on a family member and a family as a whole (Deeken, Taylor, Mangan, Yabroff, \& Ingham, 2003). A study reported that women react to caregiving with a greater tendency to become distressed and to feel burdened by caregiving. Women by nature are nurturers and get emotionally drawn into their activities. They also put unreasonable burdens on themselves while sacrificing their own physical and emotional needs in a bid to provide the best for the child or family member. This subjective caregiving burden may be associated with maternal depression. In this study, most mothers experienced depressive symptoms. Those who were taking care of their children were mostly mothers in the pediatric wards $(41.8 \%)$. It was well recognized that caregiving could adversely affect the psychological adjustment of the family caregiver as well as increased caregiver burden (Weitzner, McMillan, \& Jacobsen, 1999). Caregiver burden was generally used to refer to the physical, psychological, social and /or financial reactions that could be experienced in giving care (Hinds, 1985).

\section{CONCLUSION}

Age of the caregivers was noted to increase the depression levels. From the study, older caregivers were found to have more depressive symptoms than younger caregivers. It is clear from the study that those who are 30 years and above were more and they had high depression levels. The findings also showed that the duration of caregiving affects caregivers' level of depression. From the study, the longer the period of caregiving the more the depressive symptoms. Caregiver relationship with the patient also contributed to depression levels. It was noted that caregivers of children and the wives had more depressive symptoms than the rest of the categories. This may be attributed to the close attachment of the caregivers to the patient. In most cases, mothers would care for their children and their husbands which could add to the societal gender roles of the woman. Caregiving role was shouldered by close family members.

There is a high prevalence of depressive symptoms in caregivers of patients undergoing palliative care at the Kenyatta National Hospital. The severity of the depressive symptoms ranged from mild to severe with the majority experiencing symptoms of severe depression. There are various caregiver variables associated with depressive symptoms in the caregivers. Spousal caregivers have the highest prevalence of depressive symptoms. Various interventions are required to help address issues related to depression among caregivers of patients receiving palliative care. From the findings of this study, it is important that healthcare providers should not concentrate only on the patients but also on the caregivers of patients receiving palliative care because they undergo a lot of stress which contribute to their depression. The providers need to deliberately examine the caregivers for symptoms of depression and provide effective management. This not only improves the care of the provider but it also improves the care of the patient. 


\section{REFERENCES}

Aoun, S., Kristjanson, L., Currow, D., \& Hudson, P. (2005). Caregiving for the terminally ill: At what cost? Palliative Medicine, 19, 551-555.

Baider, L., Kaufman, B. P., Manor, O., EverHadani, P., \& Kaplan, A. (1996). Mutuality of fate: Adaptation and psychological distress in cancer patients and their partners. In L. Baider, C. Cooper, \& A. Kaplan, Cancer in the Family (pp. 173-186). Wiley: Chichester.

Beeson, R. (2003). Loneliness and depression in spousal caregivers of those with Alzheimer's disease versus non-caregiving spouses. Archives of Psychiatric Nursing, 17(3), 135143.

Bemporad, D. (1988). Compound caregiving: When lifelong caregivers undertake additional caregiving roles. Rehabilitation Psychology, 55(4), 409-417.

Butler, S., Turner, W., Kaye, L., Ruffin, L., \& Downey, R. (2005). Depression and caregiver burden among rural elder caregivers. Journal of Gerontological Social Work, 46(1), 56.

Cameron, J., Shin, J., Williams, D., \& Stewart, D. (2004). Brief problem-solving intervention for family caregivers to individuals with advanced cancer. Journal of Psychosomatic Research, 57, 137-143.

Chen, M., \& Hu, C. (2002). The generalizability of caregiver strain index in family caregivers of cancer patients. International Journal of Nursing Studies, 39, 823-829.

Clark, P. (2002). Effects of individual and family hardiness on caregiver depression and fatigue. Research in Nursing and Health, 25(1), 37-48.

Covinsky, K., Newcomer, R., Fox, P., Wood, J., Sands, L., \& Dane, K. (2003). Patient and caregiver characteristics associated with depression in caregivers of patients with dementia. The Journal of General Internal Medicine, 18 (12), 1006-1014.

Deeken, J., Taylor, K., Mangan, P., Yabroff, K., \& Ingham, J. (2003). Care for the caregivers: a review of self-report instruments developed to measure the burden, needs and quality of life of informal caregivers. Journal of Pain and Symptom Management, 26, 922-953.

Ferrario, S., Cardillo, V., Vicario, F., Balzarini, E., \& Zotti, A. (2004). Advanced cancer at home: caregiving and bereavement. Palliative Medicine, 18, 129-136.

Gallicchio, L., Siddiqi, N., Langenberg, P., \& Baumgarten, M. (2002). Gender differences in burden and depression among informal caregivers of demented elders in the community. International Journal of Geriatric Psychiatry, 17(2), 154-163.

Given, B., Given, C., \& Kozachik, S. (2001). Family support in advanced cancer. A Cancer Journal for Clinicians, 51, 213-231.

Grunfeld, E., Coyle, D., Whelan, T., Clinch, J., Reyno, L., Earle, C., . . . Glossop, R. (2004). Family caregiver burden: Results of a longitudinal study of breast cancer patients and their principal caregivers. Canadian Medical Association Journal, 170, 1795-1801.

Hinds, C. (1985). The needs of families who care for patients with cancer at home: are we meeting them? Journal of Advanced Nursing, $10,575-581$.

Rivera, H. (2009). Predictors of cancer caregiver depression symptomatology. Nairobi, Kenya: Graduate School Theses and Dissertation.

Seymour, J., Clark, D., \& Winslow, M. (2004). Morphine use in cancer pain: from last resort to gold standard. Poster presentation at the Third Research Forum of the European Association of Palliative Care. Palliative Medicine, 18(4), 378.

Shanks-McElroy, H., \& Strobino, J. (2001). Male caregivers of spouses with Alzheimer's disease: Risk factors and health status. American Journal of Alzheimer's Disease and Other Dementias, 16(3), 167-175.

Siegel, K., Karus, D., Raveis, V., Christ, G., \& Mesagno, F. (1996). Depressive distress among 
the spouses of terminally ill cancer patients. Cancer Practice, 41(1), 25-30.

Weihs, K., Fisher, L., \& Baird, M. (2002). Families, health, and behaviour. Families, Systems \& Health, 20(1), 7-46.

Weitzner, M., McMillan, S., \& Jacobsen, P. (1999). Family caregiver quality of life: differences between curative and palliative cancer treatment settings. J Pain Symptom Manage, 17(6), 418-428.

Weitzne, L., \& Leahey, M. (2005). The three most common errors in family nursing: How to avoid or sidestep. Journal of Family Nursing, 11(2), 90-101. 